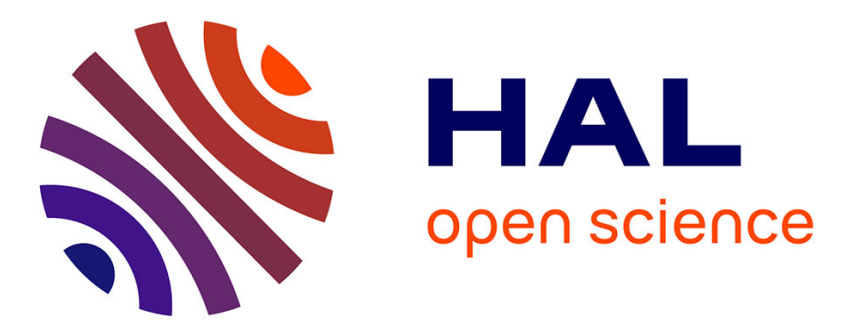

\title{
Electronic properties of non-doped and doped polyacetylene films studied by E.S.R.
}

\author{
P. Bernier, M. Rolland, M. Galtier, A. Montaner, M. Régis, M. Candille, C. \\ Benoit, M. Aldissi, C. Linaya, F. Schué, et al.
}

\section{- To cite this version:}

P. Bernier, M. Rolland, M. Galtier, A. Montaner, M. Régis, et al.. Electronic properties of nondoped and doped polyacetylene films studied by E.S.R.. Journal de Physique Lettres, 1979, 40 (13), pp.297-301. 10.1051/jphyslet:019790040013029700 . jpa-00231628

\section{HAL Id: jpa-00231628 https://hal.science/jpa-00231628}

Submitted on 1 Jan 1979

HAL is a multi-disciplinary open access archive for the deposit and dissemination of scientific research documents, whether they are published or not. The documents may come from teaching and research institutions in France or abroad, or from public or private research centers.
L'archive ouverte pluridisciplinaire HAL, est destinée au dépôt et à la diffusion de documents scientifiques de niveau recherche, publiés ou non, émanant des établissements d'enseignement et de recherche français ou étrangers, des laboratoires publics ou privés. 


\title{
Electronic properties of non-doped and doped polyacetylene films studied by E.S.R.
}

\author{
P. Bernier, M. Rolland, M. Galtier, A. Montaner, M. Regis, M. Candille, C. Benoit \\ Groupe de Dynamique des Phases Condensées $\left({ }^{+}\right)$ \\ M. Aldissi, C. Linaya, F. Schué, J. Sledz, J. M. Fabre $\left(^{*}\right)$ and L. Giral $\left(^{*}\right)$ \\ Laboratoire de Chimie Macromoléculaire \\ (*) Laboratoire de Chimie Structurale Organique \\ U.S.T.L., place Eugène-Bataillon, 34060 Montpellier Cedex, France
}

(Reçu le 30 mars 1979, accepté le 14 mai 1979)

\begin{abstract}
Résumé. - Des films de polyacétylène ont été synthétisés et dopés avec l'iode et le pentafluorure d'antimoine, à l'aide des procédés chimiques usuels. Le dopage à saturation conduit à des valeurs de conductivité d'environ 120 et $25(\Omega \mathrm{cm})^{-1}$ à température ambiante, respectivement pour $\mathrm{I}_{2}$ et $\mathrm{SbF}_{5}$. La Résonance Electronique de Spin des échantillons cis et trans, dopés et non-dopés, a été étudiée. Une analyse qualitative des résultats permet une meilleure compréhension des propriétés électroniques de ces polymères dopés, fortement inhomogènes et hautement conducteurs.
\end{abstract}

\begin{abstract}
Cis-polyacetylene films have been synthetized and doped with iodine and antimony penta fluoride, using usual chemical techniques. Doping, leads, after saturation, to conductivity values of about 120 and $25(\Omega \mathrm{cm})^{-1}$ at room temperature, respectively for $\mathrm{I}_{2}$ and $\mathrm{SbF}_{5}$ dopants. The E.S.R. of cis- and trans-, non-doped and doped $(\mathrm{CH})_{x}$ films has been studied. A qualitative analysis of the results allows a better understanding of the electronic properties of these extremely non homogeneous and highly conductive doped polymeric materials.
\end{abstract}

1. Introduction. - Doping of polyacetylene films with donor or acceptor molecules [1] is known to allow the conductivity to vary from $10^{-8}-10^{-6}$ to $10^{2}-10^{3}(\Omega \mathrm{cm})^{-1}$ at room temperature, the upper values being comparable with those obtained on polycrystalline organic conductors such as TTFTCNQ [2] and inorganic polymeric systems such as $(\mathrm{SN})_{x}$ [3]. Considerable interest is now focussed in several applied research laboratories on the systematic study of such materials, varying the nature of the doping element, using copolymers of acetylenes and various other monomers, etc... This interest is greatly warranted by the promising mechanical and electrical properties in addition to the ease of the synthesis and doping processes.

Beyond these aims a fundamental interest concerns some aspects of the transport properties connected with the polymeric nature of the material. Particularly, anisotropy of the conductivity and the fact that orientation by stretching increases the conductivity

$\left({ }^{+}\right)$Laboratoire associé au C.N.R.S. of the doped samples, raise the question of the unidimensional character of the transport properties.

In fact, those materials are known to be highly inhomogeneous, as appears from density measurements and direct observation by scanning electron microscopy, leading to a model of entangled fibrils whose characteristic dimensions are of the order of a few $100 \AA$. If the transport properties depend on the intrinsic properties of the more or less crystalline fibrils, it has been shown that the conductivity of doped samples is principally limited by interfibrillar contacts [1]. A similar conclusion can be drawn from Hall effect measurements [4]. It has then been proposed that the intrinsic transport properties of the fibrils are much more effective than those appearing from macroscopic conductivity measurements.

E.S.R. is a technique which can bring information on the local properties of a system containing unpaired localized electrons or conduction electrons.

In strongly irradiated saturated polymers, like polyethylene, singlet spectra are observed, as a consequence of the high number of conjugated double bonds created by irradiation [5]. Singlet'spectra have 
also been observed on cis- and trans- $(\mathrm{CH})_{x}$, which implies that polymeric chains are long, while the unpaired electrons were determined to be distinct from the carriers responsible for electronic conduction [6].

Very recently Goldberg et al. [7] have studied the E.S.R. of undoped and $\mathrm{AsF}_{5}$ doped polyacetylene, utilizing an apparatus which allowed in-situ doping in the microwave cavity. In the light of their results they proposed that the signal observed on undoped samples arises from a mobile defect in the $\pi$ electron system. On heavily doped samples, their experimental data was consistent with the existence of Pauli paramagnetism resulting from metallic behaviour. Weinberger et al. [8], with additional static magnetic susceptibility measurements have evidence for such a Pauli type contribution in heavily $\mathrm{AsF}_{5}$ doped samples. We present here some E.S.R. experiments performed on cis- and trans-, $\mathrm{I}_{2}$ and $\mathrm{SbF}_{5}$ doped $(\mathrm{CH})_{x}$, in the temperature range $130 \mathrm{~K}$ to $300 \mathrm{~K}$, focussing our attention on the magnetic properties of the resonant spins, in order to identify their nature.

2. Synthesis and characterization of the $(\mathrm{CH})_{x}$ films. - Polyacetylene films were obtained by the method described by Ito et al. [9], using the $\mathrm{Ti}\left(\mathrm{OC}_{4} \mathrm{H}_{9}\right)_{4}+\mathrm{Al}\left(\mathrm{C}_{2} \mathrm{H}_{5}\right)_{3}$ homogeneous catalytic system in toluene (with molar ratio $\mathrm{Al} / \mathrm{Ti}=4$ ). Polymerization has been performed at temperatures between $-50^{\circ} \mathrm{C}$ and $-78^{\circ} \mathrm{C}$ favouring the cisisomer. Trans-isomerization was obtained by holding the cis-isomer (prepared at $-78^{\circ} \mathrm{C}$ ) in $\mathrm{n}$-hexadecane at $200{ }^{\circ} \mathrm{C}$ for $90 \mathrm{~min}$. Various thicknesses (between 0.10 and $0.2 \mathrm{~mm}$ ) have been obtained, depending on the polymerization time (15 to $30 \mathrm{~min}$ ) and acetylene pressure (between 0.1 and $1 \mathrm{~atm}$ ).

In order to verify the sample quality, electrical conductivity at room temperature, infrared and visible spectroscopy (by reflection) have been utilized. The dc-conductivity measurements were performed using the four probe method, with gold wires and gold paints. The results obtained on undoped

$$
c i s-(\mathrm{CH})_{x}\left(2 \times 10^{-9}(\Omega \mathrm{cm})^{-1}\right)
$$

and

$$
\text { trans- }(\mathrm{CH})_{x}\left(6 \times 10^{-6}(\Omega \mathrm{cm})^{-1}\right)
$$

are in good agreement with values given by different authors [1], [6].

Cis- $(\mathrm{CH})_{x}$ films were doped in two ways. Firstly, by direct contact with $\mathrm{I}_{2}$ vapour when the conductivity, which was measured in-situ during the doping process, reached a saturation value at $50(\Omega \mathrm{cm})^{-1}$ after five hours. Secondly, cis- $(\mathrm{CH})_{x}$ films were doped in saturated solutions of $\mathrm{I}_{2}$ and $\mathrm{SbF}_{5}$ in pentane, providing conductivity values of $\sim 120(\Omega \mathrm{cm})^{-1}$ and $\sim 25(\Omega \mathrm{cm})^{-1}$ respectively. The value obtained at room temperature, as well as the activation energy $E_{\mathrm{a}} \sim 10 \mathrm{meV}$ deduced from the temperature dependence of the conductivity, with $\mathrm{I}_{2}$ dopant are in good agreement with published results [1], [10], while $\mathrm{SbF}_{5}$ doping is not cited.

Infrared and visible spectroscopy performed at $200 \mathrm{~K}$ to avoid any transformation of the samples, were respectively utilized to check the cis and trans content and the energy gap $E_{\mathrm{g}}$ of the samples. Fresh $(\mathrm{CH})_{x}$ films prepared at $-78^{\circ} \mathrm{C}$ have been shown to have a cis-isomer content of the order of $90 \%$. Thermal treatment of the cis-isomer as described above, has led to a trans content better than $80 \%$. Working with samples of large thickness, we have used the anomaly of the reflecting power to estimate $E_{\mathrm{g}}$. Values of $\sim 1.3 \mathrm{eV}$ for non-doped cis- $(\mathrm{CH})_{x}$ and $\sim 1.5 \mathrm{eV}$ for iodine doped samples are in good agreement with those obtained by different authors [1], [6].

Thermal treatment in the range 290 to $390 \mathrm{~K}$ as well as aging at room temperature and atmospheric pressure gave strongly degraded samples : in addition to the expected cis-trans isomerization we observed an important oxidation (as shown by IR spectra) and a decrease of the conductivity. Therefore, fresh samples were sealed in glass tubes under vacuum and kept at $T \sim 255 \mathrm{~K}$. E.S.R. results have been obtained with such samples.

The essential characteristics of our samples are summarized in table I. Impurity contents have been determined by elemental analysis and/or weight increase of the samples after the doping process. The $c i s /$ trans content of the doped samples is unknown as it seems that the doping process induce an isomerization from cis to trans [1].

Table I. - Essential characteristics of the film samples used for E.S.R. experiments.

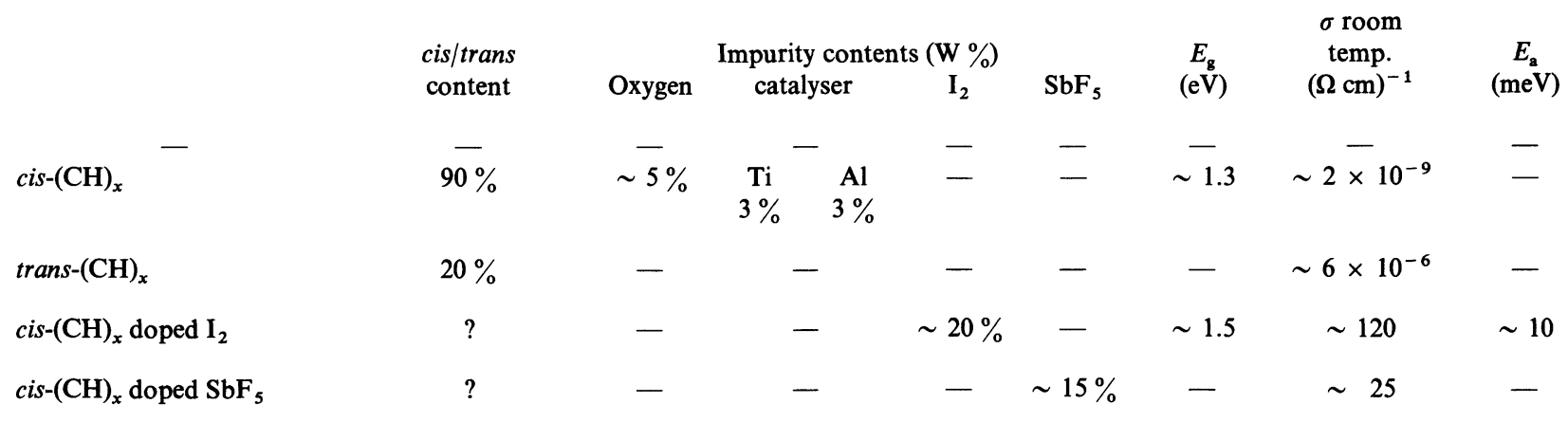


3. Experimental results. - E.S.R. spectra have been recorded on an ERIO Brucker spectrometer working at $9 \mathrm{GHz}$. Maximum hyperfrequency power was $30 \mathrm{~mW}$.

Temperature could be varied in the range $100 \mathrm{~K}$ to $300 \mathrm{~K}$ using a standard nitrogen gas flow cryostat. Temperature stability and accuracy were of the order of $1 \mathrm{~K}$.

3.1 NON-DOPED cis- AND trans- $(\mathrm{CH})_{x}$. - The observed spectra had the following characteristics [11] :

a) A Lorentzian shape with a $g$-value $\left({ }^{1}\right)$ very close to the free electron value $g=2.0023$.

b) The intensity $I$ of the signal corresponds roughly to $10^{19} \mathrm{~g}^{-1}$ resonant electrons. Its dependence on the hyperfrequency field amplitude $H_{1}$ at room temperature presents a saturation effect as $\mathrm{d} / / \mathrm{d} H_{1}$ is not constant above a hyperfrequency power of $8 \mathrm{~mW}$ (Fig. 1). Such an effect is expected when, in the saturation factor $\left(1+g^{2} \mu^{\mathrm{b}} \hbar^{-2} H_{1}^{2} T_{1} T_{2}\right)^{-1}$ which enters the measured intensity, the second term in the brackets becomes of order unity $\left(T_{1}\right.$ and $T_{2}$ are the spin lattice and spin-spin electronic relaxation times respectively).

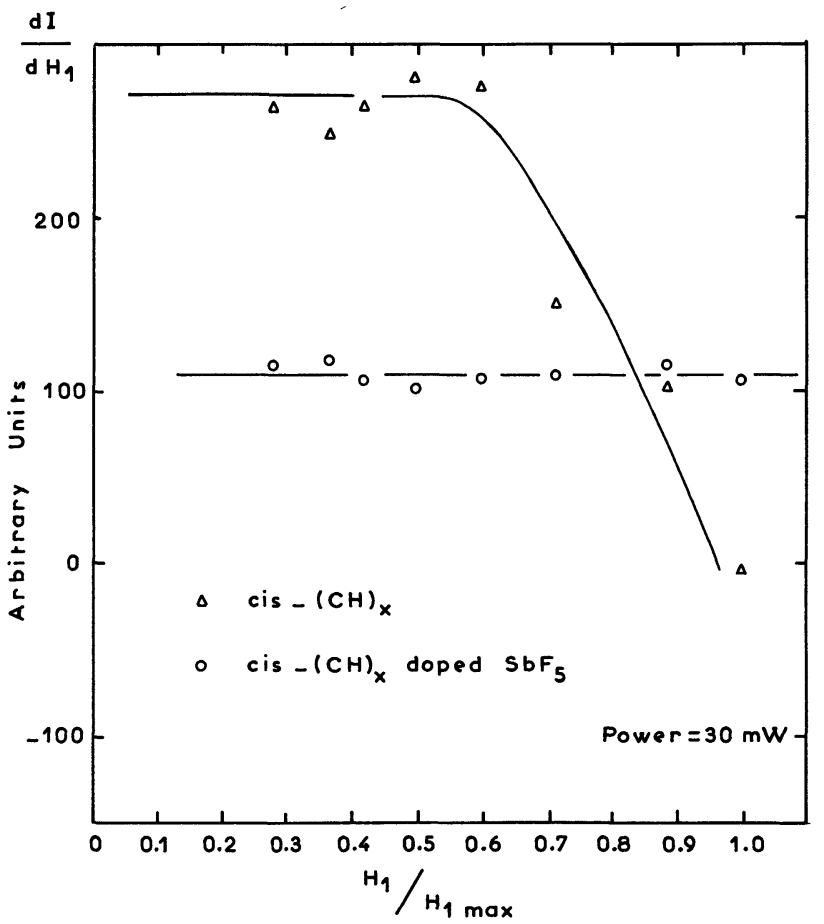

Fig. 1. - The derivative of the E.S.R. signal intensity at room temperature with $H_{1}$ amplitude is plotted versus $H_{1}$. It is expected to be constant as saturation does not occur. Any deviation from this behaviour arises when

$$
\frac{g^{2} \mu_{\mathrm{b}}^{2}}{\hbar^{2}} H_{1}^{2} T_{1} T_{2} \text { is of the order of unity [11]. }
$$

( $\left.{ }^{1}\right)$ The $g$-value of the spectra of a liquid solution of the ZieglerNatta catalyst used during polymerization was close to 1.97 , which indicates that contributions from $\mathrm{Ti}^{3+}$ residual impurities, if present in such a state in $(\mathrm{CH})_{x}$ films, are more than 100 gauss away from the observed signal. Any attempt to observe a signal close to the $\mathrm{Ti}^{3+} g$-value in the solid polymer has been unsuccessful, probably due to the oxidation of traces of the catalyst. c) The width $\Delta H_{\mathrm{pp}}$ (defined as the distance in gauss between the peaks of the absorption derivative) at room temperature is $(8 \pm 0.5) \mathrm{G}$ for the cis-isomer and $(1.4 \pm 0.2) \mathrm{G}$ for the trans-isomer. These values do not vary significantly as the temperature is lowered to $150 \mathrm{~K}$.

d) The spin susceptibility $\chi(T)$ as deduced from the spectrum parameters

$$
\left(\chi \propto(\text { linewidth })^{2} \times(\text { amplitude })\right)
$$

presents a Curie type temperature $T$ dependence : $\chi \propto T^{-1}$.

Concerning the shape, $g$-value, intensity and linewidth, our results are in good agreement with those reported by some authors [5], [6], [7], while some disagreement, probably due to different sample preparation and treatment, exists with others [12], [13].

3.2 DOPED cis-(CH) $)_{x}-a$ ) One essential feature of the observed spectra is their evolution with time which depends on the type of doping element. If no signal could be observed on fresh iodine doped $(\mathrm{CH})_{x}$, the sample kept in standard room conditions presented after a few days a signal close to $g=2$, whose amplitude slowly increased with time. The spectrum was non symmetric (peak amplitude in low field/peak amplitude in high field $\simeq 2$ ). This non symmetric character slowly disappeared with time. On the other hand $\mathrm{SbF}_{5}$ doped samples showed at any time a signal near $g=2$ which was slowly decreasing with time. The spectrum was also non symmetric (amplitudes ratio $\sim 1.3$ ).

b) Intensities correspond to numbers of resonant electrons 10 to $10^{2}$ (for $\mathrm{SbF}_{5}$ dopant) and $10^{2}$ to $10^{3}$ (for $I_{2}$ dopant) times smaller than in non-doped samples. No saturation effect occurs as $\mathrm{d} I / \mathrm{d} H_{1}$ is still a constant up to our $30 \mathrm{~mW}$ maximum hyperfrequency power (Fig. 1 for $\mathrm{SbF}_{5}$ case).

c) The widths $\Delta H_{\mathrm{pp}}$ are $(14 \pm 2) \mathrm{G}$ and $(2.4 \pm 1) \mathrm{G}$ for $\mathrm{I}_{2}$ and $\mathrm{SbF}_{5}$ doped $(\mathrm{CH})_{x}$ respectively. We have observed in the case of $\mathrm{SbF}_{5}$ doped samples an increase of a factor $\sim 3$ of $\Delta H_{\mathrm{pp}}$ when $T$ decreases from 300 to $150 \mathrm{~K}$. These results do not show any evolution with time.

d) The spin susceptibility deduced as above does not show any significant temperature dependence between $300 \mathrm{~K}$ and $130 \mathrm{~K}$ (Fig. 2 for the $\mathrm{SbF}_{5}$ case).

4. Discussion. - The preceding results clearly show that the behaviour of the resonant electrons are fundamentally different in non-doped and doped $(\mathrm{CH})_{x}$, posing distinct questions for the two cases.

The characteristics and temperature dependence of the spectra obtained on non-doped $(\mathrm{CH})_{x}$ are due to the presence of paramagnetic radicals, as appears 


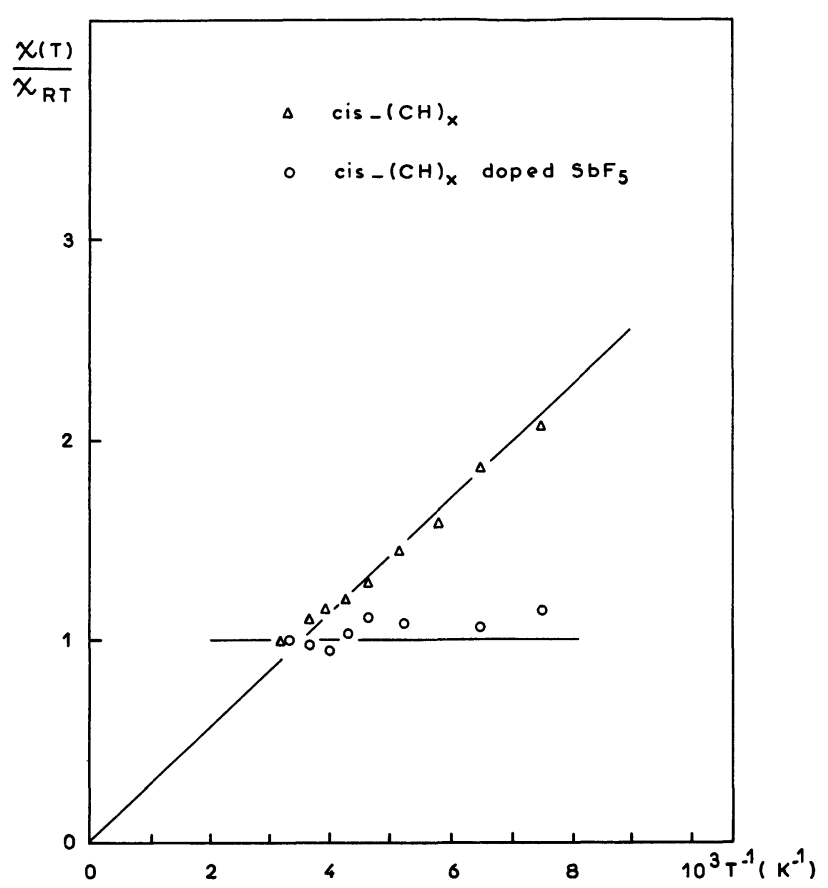

Fig. 2. - The E.S.R. susceptibility $\chi(T)$ normalized to the room temperature value is plotted versus the inverse temperature for nondoped and $\mathrm{SbF}_{5}$ doped cis- $(\mathrm{CH})_{\boldsymbol{x}}$.

from the temperature dependence of $\chi$ (Fig. 2). Ohnishi [5], by a comparison with E.S.R. spectra obtained on irradiated satured polymers, suggested the existence of radicals of the form :

$$
-\dot{\mathrm{C}} \mathrm{H}(-\mathrm{CH}=\mathrm{CH})_{n}-
$$

here $n$ refers to the number of elements in a given isomer configuration (the length of the chain is evidently expected to correspond to a greater number of elements).

Goldberg et al. [7] also supposed the existence of neutral defects of the same type :

$$
=\mathrm{CH}-\mathrm{CH}=\mathrm{CH}-\dot{\mathrm{C}} \mathrm{H}-\mathrm{CH}=\mathrm{CH}-\mathrm{CH}=
$$

spread over a domain wall containing several atomic units but of undetermined thickness.

Our data suppose the existence of one such defect for roughly $10^{3}$ monomer units. Unfortunately the number of conjugation $n$, as well as the real length of the chain are not known, due to the non solubility of the polymer in any solvent. Nevertheless Shirakawa [6] was able to estimate that $n$ would be surely greater than $\sim 100$. We then have a strong delocalization of the unpaired electrons, coherent with the absence of hyperfine structure. We suggest that the observed decrease of the width $\Delta H_{\mathrm{pp}}$ as the trans content of the $(\mathrm{CH})_{x}$ increases from $10 \%$ to $80 \%$ is a consequence of the better stability of the transisomer. The mean length of sequences of the transtype is expected to be greater than that of the cistype : both $n$ and the delocalized character of the $\pi$ electrons increase, which leads to a decrease in $\Delta H_{\mathrm{pp}}$.
It is then clear that the E.S.R. signal on non-doped samples is due to semi-delocalized unpaired electrons, on free radicals in resonant interaction with the conjugated $\pi$ electron system.

Results obtained on doped samples are much more difficult to interpret, as the exact nature of the interaction between the doping species and the polymeric chain is not well known. Nevertheless doping of $(\mathrm{CH})_{x}$ films with halogens is known to result in charge transfer with the chain and not in a direct chemical bond. The delocalized electrons system is not then disrupted, allowing for a relatively high mobility of the excess carrier [1]. In order to identify the resonant system, we can consider two possibilities : the E.S.R. spectra are due to neutral defects of the type described above, in interaction with the mobile excess carriers, or they concern the conduction carriers themselves.

Considering the first possibility, a weak interaction between the neutral defect and the conduction carriers would give a behaviour very close to the non-doped case, in contradiction with the observation of a temperature independent $\chi$ for the doped case and Curie type $\chi$ for the non-doped (Fig. 2). The strong interaction presents some analogy with the situation of localized moments in metals [14] and would be coherent with the observed susceptibilities (Fig. 2) as well as decrease of relaxation times upon doping (Fig. 1). Such a suggestion has been already made by Heeger and Mc Diarmid [15] but has been shown to fail for lightly doped samples [8].

An E.S.R. spectrum due to conduction carriers is also expected if their relaxation times $T_{1}$ and $T_{2}$ are sufficiently long, which is generally not the case in a metallic state at room temperature $[11 b]$. In fact uni-dimensional character of the transport properties, which is one essential feature of these polymeric materials, is known to lead to a strong narrowing of the spectra in comparison with tri-dimensional cases [16]. Our observed linewidth of a few gauss can be interpreted in that sense. The temperature independent susceptibility (Fig. 2) as well as the $T_{1}$ decrease upon doping (Fig. 1) are coherent with the existence of conduction electrons coupled with the lattice. Finally the non symmetric character of the spectra if interpreted at the light of the Dyson theory of E.S.R. in metals [17] would qualitatively suppose a considerably high intra-fibril conductivity. This conductivity which governs the skin effect in these conducting systems is probably several orders of magnitude greater than that measured which is not a true bulk conductivity but results from conduction through a loose tri-dimensional network of entangled fibrils. Such a conclusion is in agreement with conductivity measurements on stretched doped $(\mathrm{CH})_{x}$ where the fibrils are partially oriented [15].

A definitive choice between the two preceding possibilities is not possible as this stage. Nevertheless we note that whatever the case may be, the E.S.R. spectra are directly or indirectly influenced by the 
existence of conducting carriers. More qualitative and quantitative measurements are needed in order to investigate the electronic properties of these carriers.

Such an extended investigation of the electronic properties of doped polyacetylene, varying several experimental parameters (catalyst, experimental conditions during polymerization, monomers, doping elements) is in progress. Of course a better control of the polymerization conditions as well as a precise characterization of the samples is needed in order to consider a quantitative analysis of the E.S.R. results.

Acknowledgments. - The authors thank Dr. Collet (U.S.T.L. Montpellier) for his technical aid in E.S.R. measurements. The support for the E.S.R. equipment (Brucker Minispec ER 10) by Brucker Spectrospin France is gratefully acknowledged. One of us (P.B.) thanks Dr. D. Jérome for very helpful discussions.

\section{References}

[1] Chiang, C. K., Park, Y. W., Heeger, A. J., Shirakawa, H., Louis, E. J., MC Diarmid, A. G., J. Chem. Phys. 69 (1978) 5098.

[2] Coleman, L. B., Ph. D. thesis Philadelphie (1975).

Toombs, G. A., Phys. Rep. 40 (1978) 181.

[3] Bright, A. A., Cohen, M. J., Garito, A. F., Heeger, A. J., Appl. Phys. Lett. 26 (1975) 612

For a comparison between $(\mathrm{SN})_{x}$ and $(\mathrm{CH})_{x}$ see : STREET, G. B., Clarke, T. C., Advances in Chemistry, ACS series, to be published.

[4] Seeger, K., Gill, W. D., Clarke, T. C., Street, G. B., Solid State Commun. 28 (1978) 873.

[5] OhNishi, S. I., Ikeda, Y., Sugimoto, S. I., Natta, I., J. Polym. Sci. 47 (1960) 503.

[6] Shirakawa, H., Ito, T., Ikeda, S., Makromol. Chem. 179 (1978) 1565

[7] Goldberg, I. B., Crowe, H. R., Newman, P. R., Heeger, A. J., MC Diarmid, A. G., J. Chem. Phys. 70 (1979) 1132.

[8] Weinberger, B. R., Kaufer, J., Heeger, A. J., Pron, A., Mc Diarmid, A. G., Phys. Rev. B, to be published.

[9] Ito, T., Shirakawa, H., Ikoda, S., J. Polym. Sci. Polym. Chem. Ed. 12 (1974) $11 ; 13$ (1975) 1943.
[10] Hsu, S. L., Signorelli, A. J., Pez, G. P., Baughman, R. H., J. Chem. Phys. 69 (1978) 106.

[11] For a general review on E.S.R. see : a) ESR spectroscopy in polymer Research, RANBY, B. and RABEK, J. F. (SpringerVerlag) 1977 ; b) Electron Spin Resonance, Poole, C. P. (J. Wiley Ed.) 1967.

[12] Flandrois, S., C.R. Hebd. Séan. Acad. Sci. Paris 264 (1967) 1244. Linewidths cited in this paper are in contradiction with our results. We note that Flandrois has used powder samples which can have very different behaviour from film samples.

[13] Snow, A., Yang, N. L., Brandt, P., Weber, D., to be published.

[14] See the review on this subject : Alloul, H., Bernier, P., Ann. Phys. 8 (1974) 169.

[15] Heeger, A. J., MC Diarmid, A. G., Dubrovnik, 1978, in press.

[16] Bloch, A. N., Carruthers, T. F., Poehler, T. O., Cowan, D. O. in Chemistry and Physics of one-dimensional metals, Ed. Keller H. J. (Plenum Press) 1977.

[17] Feher, G., KIP, A. F., Phys. Rev. 98 (1954) 337. Dyson, F. J., Phys. Rev. 98 (1954) 349. 